\title{
Health Management and Clean Milk Production Practices Followed by Dairy Farmers of Nanded District of Maharashtra, India
}

\author{
Shivkumar R. Yankam and Adhiti Bhanotra* \\ Department of Veterinary and Animal Husbandry Extension, Bombay Veterinary College, \\ Parel, Mumbai-12, India \\ *Corresponding author
}

\section{A B S T R A C T}

\begin{tabular}{|c|}
\hline Keywords \\
\hline $\begin{array}{l}\text { Health management, } \\
\text { Knuckling, Softening of } \\
\text { teats, Deworming, } \\
\text { Burddizzo castrator }\end{array}$ \\
\hline Article Info \\
\hline $\begin{array}{l}\text { Accepted: } \\
30 \text { March } 2018 \\
\text { Available Online: } \\
10 \text { April } 2018\end{array}$ \\
\hline
\end{tabular}

Present study was carried out to find out various health management and milking practices followed by dairy farmers in Nanded district of Maharashtra with the sample size of total 120 dairy farmers. Respondents were selected randomly from three blocks and data were collected about health management and milking practices followed by dairy farmers and results obtained showed that $(87.5 \%)$ of dairy farmers allowed natural separation of naval cord, Only (45.83\%) farmers fed colostrum whenever newly born was able to stand on its feet and $(75.83 \%)$ respondents buried placenta while majority (90\%) of the farmers provided bedding to young ones. i.e. Paddy straw, soft murrom (soft rock). In case of milking management majority $(60 \%)$ of the respondents dried their pregnant animals two months prior to calving and (57.50\%) farmers practiced knuckling method of milking. Majority $(98.33 \%)$ of the respondents followed the practice of removing first two streams of milk from each teat. Dipping fingers into milk and softening of teats before milking was carried out by $100 \%$ all the dairy farmers.

\section{Introduction}

Dairy farming is an important component of Indian agriculture supporting livelihood of more than two-thirds of the rural population and a tool for poverty alleviation. It supplements income and provides selfemployment and thereby uplifts the socioeconomic status of rural people. Livestock rearing is one of the most important economic activities in the rural areas of the country providing supplementary income for most of the families dependent on agriculture. In addition to milk, the manure from animals provides a good source of organic matter for improving soil fertility and crop yields and most of the milk is produced by animals reared by small, marginal farmers and landless labourers. India ranks first in milk production, accounting for 18.5 per cent of world production, achieving an annual output of 163 million tonnes during 2015-16. Animal health management is an integral part of animal welfare and has a direct bearing on profits accrued from the farm. But despite having huge livestock population per capita milk production and its distribution is low as compared to other milk producing countries. This variability can be attributed to certain factors like breeds of animals, availability of 
feeds and fodder and adoption of scientific health care and management practices (Sharma, 2004). Basically, milk production depends upon a four dimensions of animal husbandry practices which includes, breeding, feeding, health care and management practices. Monitoring animal health and clean milk production practices helps in minimizing the incidence of disease and mortality which causes huge loss to the already marginalized dairy farmers. Therefore, the health care and management practices followed by the farmers play a vital role in enhancing income from dairy enterprise. Milk production can be improved by adequate feeding, scientific management and upgrading of local nondescript dairy animals.

\section{Materials and Methods}

Nanded district was purposively selected for the study as it possesses 1.1 million livestock population and ranked $8^{\text {th }}$ in terms of livestock population in Maharashtra state (BAHS 2015). But animal productivity is very low as compared to other districts' of Maharashtra because of poor network of dairy cooperatives, low productivity of non-descript animals and lack of awareness about improved dairy farming practices. For data collection three blocks namely Biloli, Degloor and Mukhed were randomly selected, from each selected blocks two villages (i.e. total six villages) were selected randomly and from each village 20 respondents were selected who had at least two milch animals at the time of study thus making a sample size of 120 respondents. An interview schedule was developed in light of the objectives of the study. The entire schedule was pre-tested in non-sampling area for elimination, alteration and modification. While conducting survey, the assistance of the local Veterinary personnel was taken. The selected farmers were interviewed by contacting them at their doorstep utilizing a pre-tested interview schedule developed for the purpose. The family members of the farmers were also involved in collection of the data. Statistical measures were used includes mean, frequency, percentage, cumulative square root frequency test (CSRT).

\section{Results and Discussion}

\section{Animal Health Management Practices}

The results of health management practices followed by the farmers in the study area are presented in (Table 1) shows that majority $(91.66 \%)$ of respondents used gunny bags for cleaning of newborn calves, $(87.5 \%)$ of dairy farmers allowed natural separation of naval cord and only (12.5\%) used sterilized blade and antiseptic solution to separate naval cord of new born calf. Similar findings were reported by Kokate and Tyagi (1991), Munish Kumar (2004), Singh et al., (2015) that majority $(95.00 \%)$ of respondents did not practice navel cord cutting and it was left to fall off naturally. 45.83 of the farmers fed colostrum whenever newly born was able to stand on its feet, it was evident from above results that majority of farmers had least concern about feeding colostrum immediately after birth and were unaware about colostrums immunological importance of immediate feeding to new born calves. Majority (75.83\%) of the respondents buried placenta, whereas $(19.16 \%)$ farmers threw away placenta in jungles. They were not aware about the disposal pattern of placenta but followed from long time. Majority $(90 \%)$ of the farmers provided bedding to young ones. i.e. Paddy straw, soft murrom (soft rock), only (45.83\%) respondents followed deworming practice whenever suggested by veterinarian. Lower rate of adoption of deworming might be due to unawareness about the harm caused by endoparasites on animal health and production. None of the dairy farmers had carried out dehorning practice of their young stock. Similar findings were reported by Rathore et al., (2009) and Singh et al., (2015), 
It may be because of lack of knowledge about recommended management practices and farmers of the study area felt that dehorning of young stock may affect their market price. Majority $(97.5 \%)$ of the dairy farmers castrated their male calves by veterinarian using burdizzo castrator and all castration were carried out between 1.5 to 3 years of age. Similar findings were reported by Tiwari et al., (2007).

Data regarding management of pregnant animals shows that majority $(60 \%)$ of the respondents dried their pregnant animals two months prior to calving while $(40 \%)$ of the farmers allowed animals to dry naturally, these findings are in consonance with findings of (Jarial et al., 2015) but contrary to this reported by Kumar et al., (2017) that majority $(87.3 \%)$ farmers followed the practice of self drying of animals. Drying off milking animals during advance stage of pregnancy preferably last two months before the commencement of next lactation is an important art of milking management, particularly for high yielding dairy animals so it needs to create awareness about this managemental practice. (66\%) of the respondents provided special attention to bedding of advanced pregnant animals and majority $(89.16 \%)$ of the farmers had kept distance between cow shed and manure pit, $(85 \%)$ of the dairy farmers had not whitewashed their animal shed, followed by (15\%) who practiced whitewashing animal shed once in a year. Similar findings were reported by Singh et al., (2015).

\section{Udder health management and clean milk production}

Clean milk production practices involves method of milking, practices for let-down of milk, washing of udder before milking, drying of udder after washing, cleanliness of milkman, removing of hairs near to udder and removing first stream of milk from each teat
(Abdessemed et al., 2016). Data presented in (Table 2) shows the results of udder health management and clean milk production practices followed by the farmers in the study area revealed that majority $(83.33 \%)$ of the dairy farmers washed their dairy animals. Because of consecutive chronic draught situation in Marathwada region cleaning of animals and shed get reduced due to severe scarcity of water. Similar findings are reported by Singh et al., (2015), majority of the respondents washed/cleaned their animals once a week $(53.33 \%)$ followed by alternate days (18.89\%), daily $(17.78 \%)$ and never $(10.00 \%)$. The practice of cleaning of udder with water before milking was done by almost all the $100 \%$ dairy farmers. Present findings are in agreement with the results of Bainwad et al., (2007), Singh et al., (2015) that cleaning of udder before milking was done by 93.89 per cent of the respondents and that too only with water. It was evident that majority $(95.84 \%)$ of the respondents did not followed the practice of removal of hair around udder and flank area, similar findings are reported by Kumar et al., (2017), Jarial et al., (2015). Results for the Cleanliness followed by dairy personnel shows that majority $(92.5 \%)$ of dairy personnel had not followed practice like cutting their nail while only 7.5 per cent personnel followed it. (32.50\%) farmers not had the habit of spitting anywhere in milking shed, while 67.5 per cent farmers did spitting anywhere in animal shed followed by $(45.83 \%)$ and $(54.16 \%)$ farmers never smoked in animal shed and during milking respectively. Similar observations were reported by Singh et al., (2015) that 93.33 per cent of the respondents never trimmed their nails before milking; while $(82.22 \%)$ of the respondents washed their hands with water before milking; only (26.67\%) were aware of not spitting near the milking place; 45.56 per cent sometimes avoided smoking or of tobacco chewing near milking place or while milking. 
Table.1 Distribution of the dairy farmers according to health management practices followed

\begin{tabular}{|c|c|c|c|}
\hline \multirow[t]{2}{*}{ S. No } & Animal Health Management practices & \multicolumn{2}{|c|}{$(n=120)$} \\
\hline & Practices & Frequency & Percentage \\
\hline & \multicolumn{3}{|l|}{ Cleaning of new born calves } \\
\hline & Gunny bag & 110 & 91.66 \\
\hline & Rice husk & 10 & 8.33 \\
\hline \multirow[t]{3}{*}{2} & \multicolumn{3}{|l|}{ Method of Naval cord separation } \\
\hline & Using sterilized blade and antiseptic solution & 15 & 12.50 \\
\hline & Naturally allowed to dry and fall off & 105 & 87.50 \\
\hline \multirow[t]{5}{*}{3} & \multicolumn{3}{|l|}{ Colostrum feeding } \\
\hline & Immediately after birth & 28 & 23.33 \\
\hline & Within one hour of birth & 31 & 25.83 \\
\hline & After 2 hours of birth & 06 & 5.00 \\
\hline & Whenever the newly born is able to stand on its feet & 55 & 45.83 \\
\hline \multirow[t]{5}{*}{4} & \multicolumn{3}{|l|}{ Disposal of foetal membrane } \\
\hline & Bury it & 91 & 75.83 \\
\hline & Burn it & 03 & 2.50 \\
\hline & Throw away & 23 & 19.16 \\
\hline & Hung on tree & 03 & 2.50 \\
\hline \multirow[t]{3}{*}{5} & \multicolumn{3}{|l|}{ Bedding to young ones } \\
\hline & Paddy straw + Soft murum & 108 & 90.00 \\
\hline & No bedding material & 12 & 10.00 \\
\hline \multirow[t]{3}{*}{6} & \multicolumn{3}{|l|}{ Deworming of calves } \\
\hline & Followed & 55 & 45.83 \\
\hline & Not followed & 65 & 54.16 \\
\hline \multirow[t]{3}{*}{7} & \multicolumn{3}{|l|}{ Dehorning practice } \\
\hline & Followed & 00 & 2.50 \\
\hline & Not followed & & 97.50 \\
\hline \multirow[t]{3}{*}{8} & \multicolumn{3}{|l|}{ Castration of male calves } \\
\hline & Followed (Burdizzo castration method done by veterinarian) & 117 & 97.50 \\
\hline & Not followed & 03 & 2.50 \\
\hline \multirow[t]{3}{*}{9} & \multicolumn{3}{|l|}{ Drying of advanced pregnant animals } \\
\hline & Dried 2 months prior to calving & 72 & 60.00 \\
\hline & Allowed to dry naturally & 48 & 40.00 \\
\hline \multirow[t]{3}{*}{10} & \multicolumn{3}{|l|}{ Bedding to advanced pregnant animals } \\
\hline & Paddy/ wheat straw+ soft murum & 80 & 66.66 \\
\hline & No bedding material & 40 & 33.33 \\
\hline \multirow[t]{4}{*}{11} & \multicolumn{3}{|l|}{ Preparations before calving } \\
\hline & Disinfect the shed & 93 & 77.50 \\
\hline & Arrange the drying material & 05 & 04.16 \\
\hline & Any other (gunny bag rapping in winters) & 22 & 18.33 \\
\hline 12 & Distance between cow shed and manure pit & & \\
\hline & Followed & 107 & 89.16 \\
\hline & Not followed & 13 & 10.83 \\
\hline 13 & White wash of animal shed & & \\
\hline & Followed (once in a year) & 18 & 15.00 \\
\hline & Not followed & 102 & 85.00 \\
\hline
\end{tabular}


Table.2 Distribution of the dairy farmers according to clean milk production practices followed

\begin{tabular}{|c|c|c|c|}
\hline \multirow[t]{2}{*}{ S. No } & \multirow[t]{2}{*}{ Practices } & \multicolumn{2}{|c|}{ Respondents $(\mathrm{n}=120)$} \\
\hline & & Frequency & Percentage \\
\hline \multirow[t]{3}{*}{1.} & \multicolumn{3}{|l|}{ Cleaning of Dairy animals } \\
\hline & Daily & 106 & 88.33 \\
\hline & Alternate day & 14 & 11.67 \\
\hline \multirow[t]{2}{*}{2.} & \multicolumn{3}{|l|}{ Cleaning of udder before milking } \\
\hline & With water only & 120 & 100 \\
\hline \multirow[t]{3}{*}{3.} & \multicolumn{3}{|c|}{ Removal of hair around udder and flank regularly } \\
\hline & Followed & 05 & 4.16 \\
\hline & Not followed & 115 & 95.84 \\
\hline \multirow[t]{10}{*}{4.} & \multicolumn{3}{|l|}{ Cleanliness followed by dairy personnel } \\
\hline & \multicolumn{3}{|l|}{ Cut nails } \\
\hline & Followed & 111 & 92.50 \\
\hline & Not followed & 09 & 7.50 \\
\hline & \multicolumn{3}{|l|}{ No Spitting around in shed } \\
\hline & Followed & 81 & 32.50 \\
\hline & Not followed & 39 & 67.50 \\
\hline & \multicolumn{3}{|l|}{ No Smoking/tobacco chewing } \\
\hline & Never smoke & 55 & 45.83 \\
\hline & Sometimes & 65 & 54.16 \\
\hline \multirow[t]{5}{*}{5.} & \multicolumn{3}{|l|}{ Method of milking } \\
\hline & Knuckling method & 69 & 57.50 \\
\hline & Stripping method & 30 & 25.00 \\
\hline & Full hand milking & 20 & 16.66 \\
\hline & Machine milking & 01 & 0.83 \\
\hline \multirow[t]{4}{*}{6.} & \multicolumn{3}{|c|}{ Keep the animal standing after milking for at least 15 minutes } \\
\hline & Followed & 78 & 65 \\
\hline & Not followed & 22 & 18.33 \\
\hline & Don't know the importance of this method & 20 & 16.67 \\
\hline \multirow[t]{3}{*}{7.} & \multicolumn{3}{|c|}{ Remove first two stream of milk from each teats } \\
\hline & Followed & 118 & 98.34 \\
\hline & Not followed & 02 & 1.66 \\
\hline \multirow[t]{2}{*}{8.} & \multicolumn{3}{|l|}{ Softening of teats before milking } \\
\hline & Dipping fingers into milk & 120 & 100.00 \\
\hline
\end{tabular}

Majority (57.50\%) farmers practiced knuckling method of milking. Similar findings were reported by Kumar et al., (2014), contrary to these reported by (Kumar et al., 2014), (Mathur et al., 2010). This might be due to lack of awareness of full hand milking and easiness in practicing knuckling and farmers are not much aware about the advantages of the full hand milking method. In view of above facts, there is a need to educate dairy farmers about the new technology of managemental practices through conducting demonstration, trainings or planned extension programmes and dairy 
farmers must be educated that knuckling is a wrong method of milking which may lead to teat injury and mastitis in long term. Majority (78.00\%) of the respondents kept their animal standing after milking while $(22 \%)$ of the farmers didn't kept animal standing after milking and interestingly (20\%) of farmers didn't knew about the importance of keeping animal standing after milking. This finding is in line with Manjusha et al., (2015). There is a need to make awareness amongst them about managemental diseases caused by microorganism entering through opened teat canal immediately after milking. Majority (98.33\%) of the respondents followed the practice of removal of first two streams of milk from each teats while only 1.66 per cent of the farmers had not followed this practice while dipping fingers into milk and softening of teats before milking was carried out by $100 \%$ all the dairy farmers.

It can be concluded that respondents were unaware about the scientific healthcare and management practices for production purpose which includes the studied respondents were not following the practice of feeding colostrums to young ones immediately after birth and they never dewormed their calves while none of the dairy farmers had carried out dehorning practice of their young stock. Dairy personnel had not followed the personal hygiene practices like cutting their nail, clean clothes and not spitting in around the milking place.

Still Majority of the farmers practiced knuckling method of milking. From the above findings, it could be concluded that health management status in the study area was not quite satisfactory especially with regards to the adoption of health management practices like feeding of colostrum, naval cord cutting, deworming and right age castration and prophylactic measures, so there is need to raise the level of awareness amongst farmers' regarding improved health management practices for their animals and maintenance of hygienic environment for animal.

\section{Acknowledgement}

Present research paper is a part of the M.V. Sc. thesis submitted to Maharashtra Animal and Fishery Sciences University, Nagpur (Maha. sate) by the first author. The authors are profoundly thankful to the Bombay Veterinary College, Head of the Department for Veterinary and animal husbandry extension for supporting the research. The author also express gratitude who provided the valuable guidance and shared their knowledge experience to complete this study.

\section{Conflict of Interest}

The authors hereby declared that there is no conflict of interest

\section{References}

Abdessemed D, Avdeenko VS, Avdeenko AV (2016). Diagnosis and therapy of subclinical mastitis in lactating dairy cows. Journal of Animal. Health. Prod. 4(3): pp. 95-100.

Bainwad D. V., B. R. Deshmukh, B. M. Thombre D. S. Chauhan, 2007 Feeding and management practices adopted by buffalo farmers under watershed area. Indian Journal of Animal Research, 41(1), pp. 68-70.

Bashir BP (2013). Milking management practices followed in selected areas of the Kottayam district of Kerala state. Journal of Life Sciences. 5(1): pp. 5355.

Basic Animal Husbandry \& fisheries statistics, 2015 Government of India, Ministry of agriculture department of animal husbandry, dairying and fisheries krishibhawan, New Delhi. 
Jarial S, Kumar A, Padmakumar V, 2015, Assessment of feeding practices, nutritional status and gap for dairy buffaloes in hilly districts Tehri Garhwal and Pithoragarh of Uttarakhand, India, Indian Journal of Animal Science. 83(9): pp. 960-963.

Kishore K., Mahender, M. and Harikrishna C. 2013 A study on buffalo management practices in khammam district of Andhra pradesh. Buffalo Bulletin (June 2013), 32(2).

Kokate, K. D. and Tyagi K. C. 1991 Dairy farming practices of tribal cattle owners. Indian Journal of Extension Education 27 (3 and 4): 70-75.

Kumar S. 2014 Studies on breeding, health care and milking management practices adopted by the dairy owners in Shahdol district of MP, India. International Research Journal of Biological Sciences. 3(10).

Kumar, M. 2015 Buffalo healthcare management practices followed by the farmers of Ferozepur district of Punjab, India. Indian Journal of Animal Research, 49(3), pp- 413-415.

Mathur P, 2010 Problems and prospects of improved cattle management in arid western plain zone of Rajasthan.
Rathore R. S., R. Singh and A. Tiwari 2010 Studies on various existing managemental practices followed by the crossbred cattle owners. Indian Journal of Animal Production and Management, 26(1/2), pp. 85-88.

Rathore R. S., R. Singh, R. N. Kachwaha, and R. Kumar. 2010 Existing management practices followed by the cattle keepers in Churu district of Rajasthan. Indian Journal of Animal Sciences, 80(8), pp. 798-805.

Sabapara G. P., A. B. Fulsoundar and V. B. Kharadi. 2014 Milking and Health Care Management Practices Followed by Dairy Animal Owners in Rural Areas of Surat District.

Singh M., R. Chakravarty, A. Bhanotra, and M. Kumar. 2015 Dairy animal health and housing management practices followed by tribal dairy farmers of Ranchi, Jharkhand. International Journal of Farm Sciences, 5(3), pp. 199206.

Tiwari R, M. C. Sharma and B. P. Singh. 2007 Buffalo calf health care in commercial dairy farms: a field study in Uttar Pradesh (India). Livestock Research for Rural Development, volume 19, Article \#38.

\section{How to cite this article:}

Shivkumar R. Yankam and Adhiti Bhanotra. 2018. Health Management and Clean Milk Production Practices Followed by Dairy Farmers of Nanded District of Maharashtra, India. Int.J.Curr.Microbiol.App.Sci. 7(04): 3592-3598. doi: https://doi.org/10.20546/ijcmas.2018.704.405 